\title{
Hartmann Kolostomi Kapatılması Esnasında Gelişen Mesane Perforasyonu; Bir Olgu Sunumu
}

Mehmet SARAC

\begin{abstract}
$\ddot{\mathbf{O} z}$
Hartmann procedürü (HP) başlıca kolon obstriksiyon ve perforasyonlarını içeren çeşitli kolonik aciller için uygulanan bir yöntemdir. HP'ne bağlı stoma bağırsak sürekliliği ikinci bir operasyon ile sağlanıncaya kadar geçici olarak düşünülür ancak HP uygulanan bazı hastalarda stoma kapatılması yapılamıyabilir. Bu olgumuzda 52 yaşında ileus nedeniyle acil servise başvuran tarafimıza HP uygulanmış, post operatif 1. Yılında ostomisi kapatılmak üzere kliniğimize yatırılarak operasyona alındı. $\mathrm{Bu}$ esnada mesane perforasyonu gelişti. Olgumuzu tıp literatürüne bir katk1 olması nedeniyle sunmayı amaçladık. HP kapatılması girişimi sırasında gelişen mesane perforasyonu irdelendi.
\end{abstract}

Anahtar Kelimeler: Hartmann procedür kapat1lması, mesane perforasyonu, rektum ca,
Yayın Bilgisi

Gönderi Tarihi:13.10.2018

Kabul Tarihi:14.07.2019

Online Yayın Tarihi:31.12.2019

DOI: $10.26453 /$ otjhs.469873

Sorumlu Yazar

Mehmet SARAÇ

Malatya Eğitim ve Araştırma

Hastanesi, Genel Cerrahi, 44090

Malatya/TURKEY

Tel: 4445634 Cep: 05064019950

Fax: +90 4223253438

E Mail: msarac44@hotmail.com

\section{Bladder Perforation During Reversal Of Hartmann's Procedure; A Case Report}

Mehmet SARAC $^{1}$

\begin{abstract}
The Hartmann procedure is used for various colonic emergencies, including mainly colon obstruction and perforation. HP is technically reversible, and surgeons often consider the stoma associated with this procedure as being temporary until bowel continuity is restored by a second operation. Some of the patients who undergo HP, however, will not undergo stoma closure. In this case, a 52-year-old patient who underwent HP was admitted to the emergency department due to ileus, and he was hospitalized in our clinic to close the ostomy in the first postoperative year. During the operation bladder perforation developed. We aimed to present our case as a contribution to the medical literature. Bladder perforation during reversal of HP is evaluated.
\end{abstract}

Keywords: Reversal of Hartmann's procedure, bladder perforation, rectum ca
Article Info

Received:13.10.2018

Accepted:14.07.2019

Online Published: 31.12.2019

DOI: $10.26453 /$ otjhs.469873

Corresponding Author Mehmet SARAÇ

Malatya Eğitim ve Araştırma Hastanesi, Genel Cerrahi, 44090 Malatya/TURKEY

Tel: 4445634 Cep: 05064019950

Fax: +904223253438

E Mail: msarac44@hotmail.com

\section{GİRIS}

Hartmann prosedürü (HP) ilk defa 1921 yılında Dr. Henry Albert Hartmann tarafından tanımlanmıştır; malign tümöre bağlı kolonik obstriksiyon nedeni ile acil opere edilmiş iki hastada sigmoid rezeksiyon ile rektal güdüğün sütüre edilip bırakıldığı ve kolostomi açıldığı rapor edilmiştir. HP daha sonra başlica kolon obstriksiyon ve perforasyonlarını içeren bazı kolonik aciller için uygulanan bir yöntem olmuştur. ${ }^{1}$ HP teknik olarak geri dönüşümlüdür, cerrahlar HP'ne bağl1 stomayı bağırsak sürekliliği ikinci bir operasyon ile sağlanıncaya kadar geçici olarak düșünürler. Bununla beraber HP 
uygulanan bazı hastalarda stoma kapatılmasına gidilmez. $^{2}$ Hangi HP kapatılmasının mümkün olacağı yönünde yerleşik bir kural yoktur, karar genellikle hastanın bireysel özeliklerine göre cerrah tarafindan verilir. ${ }^{3}$ HP sonrası re-anastomoz teknik olarak zahmetli ve anlamlı mortalite ve morbidite ile ilişkili olarak bildirilmiştir, morbidite ve mortaite oranları $\% 0-75$ ve \%0-28 oranlarında bildirilmiştir. ${ }^{3}$ Ayrıca \%13-69 oranlarında ya başarısız reanastomoz veya tekrara re-anastomoz düşünülmemesi sebebi ile HP sonrası kalıcı stoma oranları bildirilmiştir. Hastada kısa rektal güdük bırakılması ve daha önce radyoterapi görmüş olması HP kapanması esnasında zorluklara yol açmaktadır. ${ }^{4} \mathrm{Bu}$ olgumuzda HP kapatılması sirasinda gelişen mesane perforasyonun sebeplerini irdelendi.

\section{OLGU}

Hastadan onam alındı. 52 yaşında erkek hastaya yaklaşık 1 yıl önce obstiriksiyon yapmış rektum kanseri nedeni ile HP kliniğimizce uygulanmıştı. Rektumdaki kitle anüsten yaklaşık 6. cm'de başlamaktaydı. Rezeksiyon sonrası $3 \mathrm{~cm}$ uzunluğunda rektal güdük bırakılmıştı. Hasta operayondan sonra kemoradyoterapi aldı. Hastaya radyoterapiden yaklaşık 10 ay ve operasyondan yaklaşık 1 yıl sonra HP kapatılması için operasyona alındı. İlk başta laparaskopik olarak bakıldı ancak pevisteki yoğun ince barsak yapışıklıkları olması sebebi ile açik operasyona geçildi. Pelvisteki ince barsaklara ait yapışıklıklar ayrılırken rektal güdüğe doğru yoğun yapışıklık nedeni ile ilueumda yaklaşık 3 $\mathrm{cm}$ uzunluğunda tam kat yaralanma meydana geldi ve parsiyel rezeksiyon ve uç-uca anastomoz yapıldı. Rektal güdük izole edildiğinde pelvise gömük normalden daha kalın olarak palpe edildi acaba mesane invaze mevcut olabilir mi diye düşünüldü ancak idrar sondası çok yukarıda olması ve mesanenin sonlanıyor olarak izlenmesi nedeni ile radyoterapiye sekonder değişiklik olabileceği düşünülüp anüsten yerleştirilen stapler ile rektal güdük delindi ancak staplerin ucu yeterince dişarı çıkmadı. Stapler amvil ile birleştirilip kapatılınca tam kapanma olmaması sebebi ile amvil ayrılıp rektal güdük stapler klavuzluğunda künt ve keskin diseksiyon ile inceltilirken luminal bir alan girildiği farkedilince mesanenin perfore olduğu izlendi. Mesanede yaklaşık $0.5 \mathrm{~cm}$ çapında iki adet perfore alanı primer olarak sütürüze edilip hastaya tekrar kolostomi açıldı. Kolostomi açılmasının sebebi işlem sırasında mesanenin kalan rektal güdüğe invaze olması, diseksiyon sırasında mesane yaralanması gelişmesi ve rektal güdükten tamamen izole olarak ayrılamamas1 nedeniyle tekrardan ostomi açıld1. 


\section{TARTIŞMA}

HP kapatılması dikkatle yaklaşılması gereken majör bir abdominal operasyondur. ${ }^{5}$ Cerrahi tekniklerdeki ve laparoskopik cerrahi deneyimlerindeki gelişmelere rağmen HP sonrası barsak devamlılığının sağlanması hala anlamlı morbidite ve mortalite ile ilişkilidir. Benign bir duruma bağlı olarak açılan HP'nün kapatılma şansı malign hastalığa göre daha yüksektir. ${ }^{6}$ HP kapanma zamanını hastanın genel durumu, aldığı kemoradyoterapi, kullandığı ilaçlar, kronik hastalıklar gibi birçok durum etkilese de ilk olarak düşünülmesi gereken onkolojik durumdur. ${ }^{7}$

Hastamıza obstriksiyon yapmış rektum kanseri nedeni ile HP uygulanmıştı. Erken dönemde HP kapatılması (ilk 6 ay) ile postoperatif komplikasyon riskinde anlamlı olarak artış bulunmaktadır. Kolostomi kapatılma işlemine açıldıktan yaklaşık 12 ay sonra operasyon hazırlıkları yapıldı. Hasta operasyona alındı. Birçok cerrah reanastomoz esnasında rektal güdügüun kolay bulunması için uzun emilemeyen sütürler kullansa da postoperatif bunun yararını gösteren her hangi bir çalışma yoktur. ${ }^{6}$ Rektal güdüğün kapatılması esnasında lineer kapatıcı stapler kullanılmıştı. HP kapatılması esnasında teknik olarak zorluklar olabilir; Abdominal duvar defektine ve yoğun adezyonlara bağlı olarak cerrahi prosedürün başlangıç aşamasında organ hasarı ile karşılaşılabilir. ${ }^{8}$ Hastamız da pelvisteki yoğun yapışıklıklar nedeni ile operasyon esnasinda ileum yaralanması görüldü. Bazı hastalarda cerrahi alan radyoterapi ve kemoterapi ile etkilenebilir, kısa rektal güdük ve rektal güdüğün pelvise gömülmesi cerrahi esnasında ilave güçlüklere neden olur. Hastamızda HP kapatılması girişiminden önce kemoradyoterapi uygulanmış ve pelvise gömük kısa bir rektal güdük bulunmaktayd1. $\mathrm{Bu}$ güçlüklerin $\mathrm{HP}$ kapatılması esnasinda mesane perforasyonu gelişimine katkıda bulunduğunu düşünüldü.

\section{Sonuç}

HP kapatılması cerrahi teknikteki gelişmeler rağmen hala anlamlı morbidite ve düşükte olsa mortalite oranına sahiptir. Her HP kapatılamayabilir. Özellikle rektal güdügün k1sa olduğu, pelvise gömük olduğu ve operasyondan önce radyoterapi almış hastalar cerrahi güçlüklere katkıda bulunur. HP esnasında rektal güdüğün daha kalın hissedilmesi esnasında mesanenin yapışmış olabileceği düşünülüp mesanenin şişirilmesi ile sınırları da net belirlenip mesane yaralanması ihtimali azaltılabilir.

\section{KAYNAKLAR}

1. Horesh N, Lessing $\mathrm{Y}$, Rudnicki et al Considerations for Hartmann's reversal a nd Hartmann's reversal outcomes-a multicenter study. Int J Colorectal Dis. 
2017; 32(11):1577-1582. Doi: 10.1007/s00384-017-2897-2. Epub 2017 Sep 6. PMID:28879552.

2. Roig JV, Cantos M, Balciscueta Z, et al. Hartmann's operation: how often is it reversed and at what cost? A multicentre study. Colorectal Dis. 2011; 13(12):e396-402. Doi: 10.1111/j.14631318.2011.02738.

3. Hodgson R, An V, Stupart DA, et al. Who gets Hartmann's reversed in a regional

centre?

Surgeon. 2016;14(4):184-9.

Doi:

10.1016/j.surge.2014.11.001. Epub 2015 Jan 24.

4. Tan WS, Lim JF, Tang CL, Eu KW. Reversal of Hartmann's procedure : experience in an Asian population. Sigapore Med. 2012;53(1):46-51.

5. Brathwaite S, Kuhrt M, Yu L, et al. Retrospective Evaluation of laparoscopic versus open Hartmann's reversal: A single Instituation experience. Surg Laparosc Endosc Percutan Tech. 2015; 25(5):e156-8.

Doi:

10.1097/SLE.0000000000000201. PMID:26429059.

6. Horesh N, Rudnicki Y, Dreznik Y, et al. Reversal of Hartmann's procedure: still a complicated operation. Tech Coloproctol. 2018; 22(2):81-87. Doi: 10.1007/s10151-017-1735-4. Epub 2017 Dec 4.
7. Roe AM, Prabhu S, Ali A, et al. Reversal of Hartmann's procedure: timing and operative technique. $\mathrm{Br} \mathrm{J}$ Surg. 1991;78(10):1167-70.

8. Garber A, Hyman N, Osler T. Complications of Hartmann takedown in a decade of preferred primary anastomosis. Am J Surg. 2014;207(1):60-4. Doi: 0.1016/j.amjsurg.2013.05.006. Epub 2013 Sep 29. 